\title{
The UNFCCC at a Crossroads: Can Increased Involvement of Business and Industry Help Rescue the Multilateral Climate Regime?
}

\section{Joëlle de Sépibus*}

\section{Abstract}

Significant progress in the multilateral negotiations on climate change will only be made if civil society and in particular business and industry stakeholders actively contribute to shape it. Admitted to the international negotiations in the form of non governmental organisations (NGOs), business and industry entities continue however to be far more active at the national than at the international level. Their pro-active investment in new international policy spaces is hence highly warranted. The enhanced participation of the private sector in the multilateral climate regime, however, faces many challenges that will have to be overcome. Lessons on how to achieve an effective involvement may be drawn in particular from the Montreal Protocol on ozone-depleting substances, the World Trade Organisation, the European Union and the Asia-Pacific Partnership on Clean Development and Climate. A preliminary condition for an effective dialogue with business and industry stakeholders is a transparent process. Moreover, systematic consultations with stakeholders should be held, allowing a regular exchange of information and the effective channelling of the expertise of the private sector into the negotiation process.

Keywords: climate change, post-2012 climate regime, business, industry, multilateral climate regime, involvement, consultation

*World Trade Institute, Bern

Research for this paper was funded by the Swiss National Science Foundation under a grant to the National Centre of Competence in Research on Trade Regulation, based at the World Trade Institute of the University of Bern, Switzerland.

\section{FNDWF}

FONDS NATIONAL SUISSE

SCHWEIZERISCHER NATIONALFONDS SWISS NATIONAL SCIENCE FOUNDATION
Die Nationalen Forschungsschwerpunkte (NFS) sind ein Förderinstrument des Schweizerischen Nationalfonds. Les Pôles de recherche nationaux (PRN) sont un instrument d'encouragement du Fonds national suisse.

The National Centres of Competence in Research (NCCR) are a research instrument of the Swiss National Science Fondation. 


\section{Table of contents}

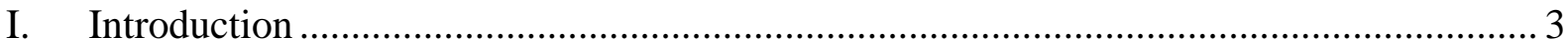

II. The current involvement of business and industry in the multilateral climate regime ...... 4

2.1. The accreditation of Business and Industry Non-Governmental Organisations

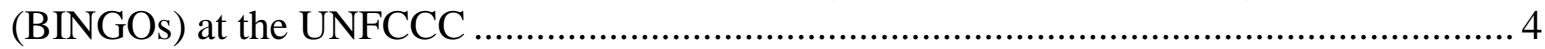

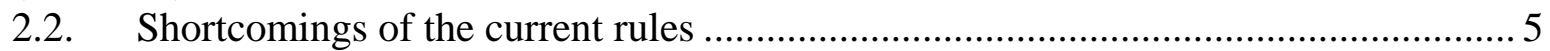

III. The challenges of increased business participation in the climate regime.................... 6

IV. Enhancing participation of business and industry stakeholders ................................. 7

4.1 Insights from stakeholder reviews and other international organisations ....................... 8

4.2 Improved transparency of the negotiation process ......................................................... 10

4.2.1 Improved access to documents and user-friendly display of information ............... 10

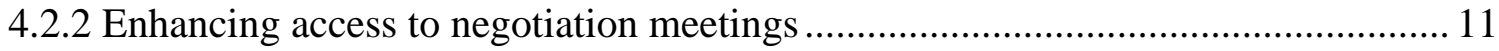

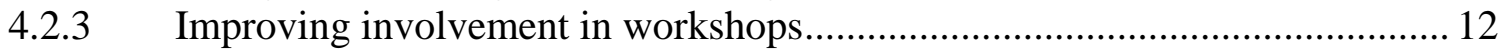

4.2.4 Mobilisation of business stakeholders through consultation processes .................. 12

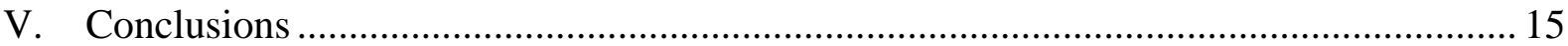




\section{Introduction}

The Copenhagen climate summit, attended by more than 120 heads of state and 40,000 accredited participants fell short of delivering the robust climate regime the world had looked for. ${ }^{1}$ Even the minimal "Copenhagen Accord", which had been elaborated in the last minute of the Conference by 26 heads of State, did not gather enough support to be adopted as a formal decision by the Parties. A sense of insecurity whether the United Nations Framework Convention on Climate change (UNFCCC) process was still able to deliver meaningful results pervaded both negotiators and stakeholders alike. The spectre that the UNFCCC process would follow the fate of the never-ending WTO Doha round loomed heavily over the negotiations. Although the following Conference of the Parties 16 (COP 16) in Cancún, where governments were able to agree upon a set of decisions, the so-called "Cancún Agreements", restored some trust in the process, the explicit rejection of this outcome by Bolivia "overcome" only thanks to a daring interpretation of the consensus principle - evidenced the fragility of the process. ${ }^{2}$

Since then the multilateral negotiation process has regained some speed and after a prolongation of more than 36 hours the negotiations at COP 17 in Durban led to the adoption of a second commitment period for the Kyoto Protocol ${ }^{3}$, an array of decisions designed to implement the Cancún Agreements ${ }^{4}$ and the "Durban Platform"5, a new negotiation track aiming at ensuring the long-term future of the climate regime. These achievements show that progress remains possible. Yet, beyond the creation of a high number of new institutions, the substance of the outcome under the Ad hoc Working group on Long-term Cooperative Action (AWG-LCA) remains rather vague and the few Parties gathering under the umbrella of the Kyoto Protocol demonstrate the fading commitment to this instrument. The decisions on the major "crunch issues" - the clarification of mitigation pledges, their overall increase of ambition, sources for long-term finance, a solid system of monitoring, verification and reporting (MRV) - were once more postponed.

The dire prospects led many notably American scholars to the conclusion that a change of venue would offer better prospects to address climate change. ${ }^{6}$ They argued that like the large array of preferential and regional trade agreements that have been concluded given the "endless cycling" of the Doha Round of the World Trade Organisation (WTO), bilateral arrangements would prove far more flexible and effective to bring about progress. So far, however, the initiatives taken in particular by the $\mathrm{G}^{7}$, the $\mathrm{G} 8+5^{8}$, the $\mathrm{G} 20^{9}$ and the AsiaPacific Partnership on Clean Development and Climate (APP) have not proven to be viable alternatives. $^{10}$

Aware of the fragility of the process and the risks of stalemate we nevertheless trust that the multilateral climate negotiations will remain an important pillar of the international climate

\footnotetext{
${ }^{1}$ Bausch et al. (2010: 17).

2 Oberthür (2010: 7).

3 / CMP.7

${ }^{4}$ 2/ CP.17.

5 1/ CP.17.

${ }^{6}$ Bausch et al. (2010: 41).

${ }^{7}$ The G8 is a group comprising Canada, France, Germany, Italy, Japan, Russia, the United Kingdom and the United States.

${ }^{8}$ G8+5 is a group which consists of the leaders of the heads of government from the G8 nations plus those from the five leading emerging economies (Brazil, China, India, Mexico and South Africa).

${ }^{9}$ The G 20 is a group of twenty finance ministers and central bank governors from 20 major economies.

${ }^{10}$ See Bausch et al. (2010: 41); Fujiwara (2012).
} 
regime for some time in the future. ${ }^{11}$ We further believe that despite the opposing views of Parties on how to tackle climate change, the distributive conflicts, the public good nature of climate change and the inherent free-riding incentives that process matters and that an improved set-up of the negotiations can help shaping a better outcome. As a matter of fact, the delicate handling of the process by the Mexican Presidency in Cancun contributed without doubt to the progress made in Cancun. But while personal engagement and diplomatic skills will always remain an important ingredient for success, it is important that the success of new negotiations does not primarily rely on the personal expertise of certain key players, but is supported by effective procedures and rules.

Based on the posit enounced by Depledge ${ }^{12}$ that a regime is ossifying, i.e. that it stops learning if it does not receive new technical input or fails to process new input in any meaningful way, our aim is to analyse how the multilateral climate process takes into account input from business stakeholders. ${ }^{13}$ The choice to shed some light on the input of this type of stakeholders is justified by the fact that business and industry entities are responsible for the bulk of GHG emissions worldwide. Accordingly, without their active contribution, both intellectual and financial, the achievement of the goals of the UNFCCC process will remain a pipe dream. Contrary to the WTO regime, which has set up a legally binding regime directly influencing business practices, the UNFCCC has, with the exception of the Clean Development Mechanism, failed to sufficiently mobilise this type of stakeholders. Hence, unless a new approach increasing both incentives and sticks is put in place, the latter will not effectively support climate friendly measures at the international level.

Given the crucial role played by business and industry for a successful long-term outcome of the challenge of climate change, we explore how their involvement may be enhanced. We will proceed as follows. First, we take stock of the current rules governing the participation of business and industry and analyse their shortcomings. Second, we examine the challenges an enhanced involvement might face. Third, drawing in particular some lessons from other international organisations, we make some reform proposals. Fourth, we conclude.

\section{The current involvement of business and industry in the multilateral climate regime}

\subsection{The accreditation of Business and Industry Non-Governmental Organisations (BINGOs) at the UNFCCC}

The participation of business and industry in the climate negotiations takes many forms. In addition to their numerous informal contacts with individual governments and negotiators ${ }^{14}$, they are admitted as observers if they fulfil the criteria set out for Business and Industry NonGovernmental Organisations (BINGOs), which means notably that they must have a nonprofit and tax-exempt status. ${ }^{15}$ Once accredited as BINGOs, they may assist the COPs' and

\footnotetext{
${ }^{11}$ See Depledge (2009).

${ }^{12}$ Depledge (2006: 2 ff.).

${ }^{13}$ See for an overview on multilateral environmental negotiations Chasek (2012).

${ }^{14}$ Certain Parties even include representatives of some companies in their delegations, providing them a direct channel to influence the position of the concerned Party.

${ }^{15}$ The right of NGOs to participate in the climate negotiations is enshrined in Art.7 par. 6 UNFCCC and in Art. 6 to 8 of the UNFCCC draft rules of procedures. The latter have never been adopted by the COP, but are applied by the Parties, with the exception of Article 42, which concerns voting rights. The draft rules of procedures are
} 
Subsidiary bodies' plenary meetings and any open-ended contact group ${ }^{16}$ unless at least one third of the Parties present object. ${ }^{17}$ This allows them to remain constantly informed about the progress of the negotiations and to report back to their members. ${ }^{18}$

Over time, BINGOs have gained the right to attend workshops ${ }^{19}$ and to submit written inputs $^{20}$, which the UNFCCC Secretariat (hereafter the "Secretariat") regularly publishes on its website. $^{21}$ They arrange private meetings with national delegates, distribute lobby documents and position papers, and even assist Parties in the formulation of legal texts in the final phases of negotiations. ${ }^{22}$ Another important channel for conveying their views is through meetings with the presiding officers ${ }^{23}$ and the Secretariat. This allows them to share their concerns in a more informal way with some of the key players of the negotiation process. ${ }^{24}$ Moreover, companies usually take advantage of the large media presence to make press releases and run exhibit stalls in the conference centres to showcase the implementation of concrete projects, using the opportunity of the well attended conferences for lobbying, networking and exchanging ideas. Finally, business and industry participate in the numerous side events that are organised on the margins of the official meetings and which often contribute to trigger a more open debate than is possible within the official negotiation fora. ${ }^{25}$

\subsection{Shortcomings of the current rules}

Despite the multiple opportunities for business and industry to observe and influence the process, the rules governing the participation of BINGOs, elaborated principally by the Secretariat $^{26}$, are often viewed as insufficient to allow the business sector to deploy its full potential. ${ }^{27}$ For instance, Schroeder et al. provide evidence that although the participation at side events offers unique opportunities "to gather all the latest thinking on a topic", their impact on negotiators remains usually quite limited. ${ }^{28}$ Also, over time, the increasing amount of constituencies recognised by the Secretariat, in particular Environmental NGOs (ENGOs),

complemented by a set of more detailed guidelines elaborated by the Secretariat as well as established practice. Both have been endorsed by the SBI. See Note by the UNFCCC Secretariat, 13 September 2011.[]

${ }^{16}$ The term has not received an official definition but is generally understood as encompassing all negotiating groups to which all Parties are invited.

${ }^{17}$ Art. 7 draft rules of procedures. Decision 18/CP.4. See Depledge (2005: 218), Vormedal (2008: 49).

${ }^{18}$ Depledge (2005: 217).

${ }^{19}$ The actual participation of NGOs in workshops is at the discretion of the Chair. See Depledge (2005: 223).

${ }^{20}$ The COP and the subsidiary bodies often invite parties to submit written inputs on issues under negotiation, which are then published on the website. See Depledge (2005: 225).

${ }^{21}$ For this purpose, the Secretariat has established a new form of UNFCCC document, which is only published on the web and not in hard copy. See Depledge (2005: 222, 225).

${ }^{22}$ See Vormedal (2008:50). Certain Parties even include representatives of some companies in their delegations, providing them a direct channel to influence the position of the concerned Party.

${ }^{23}$ The presiding officers are the persons who chair the meetings of Parties.

${ }^{24}$ It will depend mostly on the goodwill of the presiding officer whether their input is considered relevant for the negotiation process. See Depledge (2005: 224).

${ }^{25}$ Since COP 13, business also organises a so-called ‘Global Business Day’ at general COP conferences. See Fujiwara (2010: 1).

${ }^{26}$ The rules for the constituency system, the admission process, the web-only documents as well as the drafting of a code of conduct are all the result of the initiative of the Secretariat. See Depledge (2005: 230).

27 This view is shared by many businesses and academic scholars. See WBCSD et al. (2010) and Andrade et al. (2010). A more nuanced view is conveyed by Vormedal who demonstrates that BINGOS may in certain circumstances utilise very effectively networks, informal relationships with a multitude of delegations, international organisation and the Secretariat staff to put pressure on decision-makers. See Vormedal (2008: 62).

${ }^{28}$ Most negotiators can't attend the side-events because they take place simultaneously to the negotiations. See Schroeder et al (2011). The "ditch" between the official negotiations and the side-events was especially evident at the summit in Cancun in 2010, where NGOs gathered at a geographically different location than negotiators and exchanges of views between both groups were scarce. 
local government and municipal authorities (LGMAs), indigenous peoples' organisations (IPOs) and research and independent NGOs, has contributed to dilute the voice of business. ${ }^{29}$

Whereas the private sector is generally considered as crucial for promoting the transition towards a low carbon economy and fostering of resilience towards climate change of our societies it essentially remains a decision taker in the international negotiation process. As a result, the business sector is often not sufficiently organised to respond to requests for input in a coordinated and accountable way. ${ }^{30}$ While it is of course not the role of business to take part in the decision-making on par with Parties, the absence of a more pro-active involvement, which allows its expertise to be fed into the process in a more purposeful manner, is certainly unfortunate. It also entails the perverse effect that business and industry do not feel sufficiently concerned by climate change issues and remain insufficiently committed to the successful outcome of the UNFCCC process. ${ }^{31}$

This has partly been recognised by Parties in Cancun and Durban, which have invited accredited observer organisations, among them BINGOs, to submit their views with respect to several negotiation agendas, in particular regarding new market mechanisms, REDD+ and agriculture. $^{32}$ Although these provisions allow business and industry to take a more active stance, they do not fundamentally address the lack of a regular and pro-active involvement of the private sector in the climate regime.

As the negotiation process moves from formulating a broad framework for action towards more implementation, the expertise and the creativity of business and industry becomes all the more necessary, especially with respect to the mobilisation of financial resources, the design of market-mechanisms, the promotion of technology transfer and capacity building and the implementation of monitoring, review and verification (MRV) of greenhouse gas emissions (GHG). ${ }^{33}$ Moreover, involving business as early as possible in the process has the clear advantage that it will be better prepared to endorse future commitments and be able to adjust with greater speed and foresight to changing policy frameworks.

\section{The challenges of increased business participation in the climate regime}

Whereas there seems to be a broad consensus that a more active role of business in the negotiation process is desirable, opinions are divided as to how the involvement should be shaped. When examining the various options, it is important to bear in mind the challenges that an increased participation of business at the international level will have to address.

BINGOs represent a constituency of stakeholders with widely diverging views, ranging from so-called "grey" businesses ${ }^{34}$, which are opposed to mandatory GHG regulations, to "green" businesses, which consider climate mitigation and/or adaptation as an opportunity. ${ }^{35} \mathrm{~A}$ constructive contribution of many business stakeholders towards the achievement of the goals

\footnotetext{
${ }^{29}$ WBCSD et al. (2010: 30).

${ }^{30}$ WBCSD et al. (2010: 9).

${ }^{31}$ Andrade et al. (2008: 14).

${ }^{32}$ See for instance the call for inputs of observer organisation in 2/CP. 17, para 48 (registry), 65 (REDD+), 70 (agriculture), and. 75 and 79 (market mechanisms).

${ }^{33}$ WBCSD et al. (2010: 60).

${ }^{34}$ See Vormedal (2008: 39).

${ }^{35}$ See Yamin et al. (2004: 52).
} 
of the UNFCCC can thus not be taken for granted. Past experience shows indeed that especially companies depending on fossil fuel revenues have regularly attempted to slow down progress in the negotiations or even bring the whole process to a halt. ${ }^{36}$ Further, many companies, especially those operating at the international level, are concerned by questions of competitiveness $^{37}$ and "leakage" 38 and will consequently be hesitant to support mitigation policies that might put them at a disadvantage with respect to their competitors. Badly designed rules providing for enhanced business participation may thus well increase the risk of stalling of the UNFCCC process.

Greater involvement of BINGOs is also viewed with circumspection by other constituencies, especially by ENGOs. Although the deep distrust and opposition that has often characterised the relationship between these two types of constituencies in the past has probably given way to a more cooperative mindset, ENGOs will most likely oppose structures that privilege BINGOs at the expense of other constituencies.

Further, if new rules depend on an official mandate, due account will have to be taken that they require the consensus of the Parties. This may constitute an important hurdle, as the initiative taken in 1994 by New Zealand to establish a "Business Consultative Mechanism" (BCM) illustrates. ${ }^{39}$ The latter had proposed to establish a mechanism that would have allowed a closer dialogue between UNFCCC officers and major GHG emitters. No consensus could however be reached in a meeting convened by the Subsidiary Body of Scientific and Technical Advice (SBSTA) and the initiative was finally abandoned. ${ }^{40}$

Finally, all new initiatives to improve cooperation with business and industry stakeholders will be scrutinised for their budgetary and administrative implications. ${ }^{41}$ After the failure of the Copenhagen summit and the ensuing disenchantment with the multilateral process the willingness of governments to provide new supplementary finance for the UNFCCC is indeed low, and probably the more so if expenses ultimately benefit business entities that should be able to self-finance their activities. Hence, when evaluating options of increased business involvement, care will have to be taken to keep public expenditure low and to seek cooperation modalities with existing business associations and platforms.

\section{Enhancing participation of business and industry stakeholders}

Any new rules providing for increased business input should ensure a high level of transparency, non-discriminatory treatment, a balanced input in terms of size of companies and sectors, as well as geographical location. At the same time, however, they must provide the necessary flexibility to allow an effective channelling of business expertise into the negotiation process and provide enough wiggle room to address particular needs and circumstances.

\footnotetext{
${ }^{36}$ See Depledge (2008).

${ }^{37}$ Competitiveness concerns are the concerns that industries which trade heavily on the international market will lose market share to companies operating in countries with lower or no environmental standards. See Parker (2008).

${ }^{38}$ Carbon leakage concerns arise from the fear that stringent environmental regulation will force companies to move operations to countries with less stringent or no environmental policies in place. See Parker (2008).

${ }^{39}$ WBCSD et al. (2010: 32).

${ }^{40}$ FCCC/SBSTA/1996/13.

${ }^{41}$ See for a detailed summary of budget issues in the UNFCCC Yamin et al. (2004: 487)
} 
The current procedural rules laid down by the Secretariat take these various concerns into account, setting out both formal rules on representation and access to negotiation fora and allowing informal involvement with Parties and the Secretariat. They remain, however, insufficient to address the principal limitations of current business participation, which inputs remain largely sporadic, generic and uncoordinated without a consistent platform for information exchange and storage. ${ }^{42}$ The principal aim of new rules should thus focus on the creation of an architecture that increases the mobilisation of the different business stakeholder, encourages them to invest in new political spaces and foster multi-actor dialogues. ${ }^{43}$ Moreover, they should ease the access of Parties to tailor-made information that might be provided by business organisations and vice-versa. Finally, the rules should help increasing the overall transparency of the process, build trust among the different actors and create an institutional memory of business involvement. ${ }^{44}$ To sum up, the still more passive than active observer role of the business sector should evolve towards an active advisory role providing vital expertise to the negotiation process and catalysing a collective learning process.

In the following section we make some proposals how these goals could be better achieved. When examining the most appropriate forms of business participation, it is important to take into account the type of decision and the issue which is at stake as well as the stage of the negotiation process. Indeed, the need for business expertise and the possibilities to process it will vary if the decision is political or more technical ${ }^{45}$ and whether the negotiations are in a preparatory phase or in the final hours of a COP. Finally, another important distinction will have to be drawn with respect to the addressee of business input, i.e. whether the expertise is destined to the Parties or one of the newly created institutions. Indeed, whereas in the past, with the notable exception of the CDM, most substantial decisions have been taken at the level of the subsidiary bodies and/or the Conference of the Parties, the creation of new institutions, such as the Adaptation and Technology Committees or the Green Climate Fund will progressively shift the decision-making power to these new entities, once they have become operational. Although the latter remain under the ultimate authority of the COP, the bulk of decisions will take place at the level of these new entities. These changing patterns of the international climate architecture will have a direct impact on the involvement of business: the more the process will address implementation issues, the more the pro-active involvement of business will be important.

Recognising that there is no solution that fits it all, we will draw in particular on the needs expressed by business stakeholders, assess whether lessons can be drawn from other international organisations such as the European Union (EU), the World Trade Organisation (WTO) and the Organisation for Economic Co-operation and Development (OECD) and discuss some of the proposals made in the literature.

\subsection{Insights from stakeholder reviews and other international organisations}

According to a large survey of business stakeholders conducted recently by the World Business Council for Sustainable Development (WBCSD) et al. respondents considered that business should contribute both with respect to political and technical issues. ${ }^{46}$ They believed

\footnotetext{
${ }^{42}$ WBCSD et al. (2010: 65).

${ }^{43}$ Andrade et al (2010: 15)

${ }^{44}$ WBCSD et al. (2010: 65).

${ }^{45}$ See WBCSD et al. (2010: 51).

${ }^{46}$ WBCSD et al. (2010: $51 \mathrm{ff}$.)
} 
that business involvement was important to ensure that businesses contribute to the achievement of the goals of the UNFCCC and to make sure that policy instruments do not distort competition and remain economically reasonable. They finally pointed out that an active participation was necessary to gain a better understanding of the impacts of the process on their activities and to allow them to assess new business opportunities. With respect to the mode of involvement both formal and informal consultations were considered welcome.

A more pro-active involvement of the private sector has its precedents in other international organisations. In most cases, the private sector is asked to provide technical input or scientific expertise, but in others it also contributes to decision-shaping. ${ }^{47}$ For instance, under the Montreal Protocol ${ }^{48}$ business stakeholders participate in a permanent panel, ${ }^{49}$ which at the request of Parties provides technical information related to alternative technologies that allow the elimination of the use of Ozone Depleting Substances. ${ }^{50}$ At the OECD ${ }^{51}$, the Business and Industry Advisory Committee (BIAC) aims at influencing OECD policy initiatives and ensures that business needs are adequately addressed with respect to decisions that influence the legislation of its members. ${ }^{52}$ Through its policy groups, BIAC members participate in meetings, global forums and consultations with OECD delegates, committees and working groups. Further, the APP which aims at promoting green technologies in several industrial sectors has recourse to public-private task forces that are responsible for developing and implementing action plans, identifying and implementing priority actions on clean development.

In the WTO, both policy-related activities and the dispute resolution system are formally open only to state actors. In reality, however, business and industry are actively involved in the WTO process. ${ }^{53}$ Whereas in the "legislative" process, their participation occurs largely on an ad hoc basis and is a matter of discretion ${ }^{54}$, they play a considerable role in disputes submitted to the WTO. Examining two WTO disputes, Dunoff illustrates impressively how two companies, though not being formal parties to the proceedings, provided input at every stage of the process, turning the internal dispute between sovereign nations into an economic battle between economic competitors. ${ }^{55}$ More generally, the WTO has, responding to the pressure of civil society, in the last decade improved consistently the transparency of its process, providing effective and prompt dissemination of information and seeking the dialogue with the public. ${ }^{56}$ Through its sophisticated website ${ }^{57}$ a wide range of publications and audio material, focusing on the activities of the organisation and analysing the latest developments in the field of world trade, is made available, contributing thereby to a high degree of

\footnotetext{
${ }^{47}$ WBCSD et al. (2010: 49 ff.)

${ }^{48}$ The Montreal Protocol on Substances to the Vienna Convention for the Protection of the Ozone Layer is an international treaty designed to protect the ozone layer by phasing out the production of numerous substances responsible for the depletion of ozone.

${ }^{49}$ The Technical and Economic Assessment Panel.

${ }^{50}$ See on the internet under http://ozone.unep.org/teap/.

51 The OECD is a forum where governments can work together to share experiences and seek solutions to common problems to improve the social and economic well-being of the world population. See on the internet under http://www.oecd.org/pages/0,3417,en_36734052_36734103_1_1_1_1_1,00.html.

${ }^{52}$ See on the internet under http://www.biac.org/aboutus.htm.

${ }^{53}$ Dunoff (1998: 433).

${ }^{54}$ BINGOS participate in particular in symposia on topics of their interest and business leaders serve, on invitation of the Director General, as resource persons for the general meetings of the Parties. See Dunoff (1998: 451).

${ }^{55}$ Dunoff (1998: 452).

${ }^{56}$ In 2001, WTO member governments agreed at Doha to express a commitment to making the WTO's operation more transparent. See Charnovitz (2001-2002: p. 677)

${ }^{57}$ See on the internet under http://www.wto.org/
} 
accountability. Finally, online fora and social media provide effective tools of interaction both among stakeholders and between the organisation and civil society. ${ }^{58}$

An interesting business participation model is also provided by the European Union. Quittkat et $a .^{59}$, who studied its evolution over time, distinguish between three generations of consultation regimes: in an early period, the European Commission established close relations with business stakeholders by setting up an informal and ad hoc dialogue with a selective circle of actors. Typical instruments used were bilateral and multilateral meetings and hearings with experts. In the mid-1980s, consultation instruments became more institutionalized, more transparent and the EU started to promote the principle of 'partnership' with a large set of societal actors. In recent years, the Commission has extended the scope and variety of its instruments, introducing in particular online consultations, calls of exclusive expert groups and seminars as well as the organisation of encompassing conferences. In this period, the transparency of expert consultation has increased considerably and information on seminars and their participants as well as a Register of Expert Groups are currently available on the web. ${ }^{60}$

These examples testify for the wide variety of participation models existing under different international regimes, ranging from informal dialogues and conferences to internet consultations calls for expert groups to the establishment of permanent public-private panels, whose advice is systematically solicited and which, in the case of the APP, are even responsible for the implementation of certain policies. Moreover, as the example of the European Union shows, the modes of participation may evolve over time, adapting to changing circumstances but also responding to increased calls for transparency and a more democratically legitimised power of international organisations.

\subsection{Improved transparency of the negotiation process}

The preliminary condition for a meaningful business involvement is an open access to all relevant information with respect to the negotiation process. This includes inter alia that negotiation documents are made public on the web and that relevant BINGOs may assist crucial negotiating sessions be it physically or virtually.

\subsubsection{Improved access to documents and user-friendly display of information}

Although the Secretariat has improved over time the access to written documents by posting all official documents on the web ${ }^{61}$, in the final negotiation sessions of the COP and the Subsidiary Bodies Parties work generally with so-called Conference room papers or nonpapers which are only distributed to Parties on paper. Although some NGOs, which have developed close ties to Party delegates, usually succeed in getting hold of a copy ${ }^{62}$, most external stakeholders can't access them. This practice, which is mostly motivated by reasons of expediency and confidentiality, leads to a discriminatory access for external stakeholders to relevant information.

\footnotetext{
58 The Global Accountability Report gave the WTO high marks for its website and overall accountabiltiy. See Charnovitz (2001-2002: p. 677)

${ }^{59}$ See in particular Quittkat et al. (2008).

${ }^{60}$ See on the internet under http://ec.europa.eu/transparency/regexpert/.

${ }^{61}$ See for a typology of documents Yamin et al. (2004: 447).

${ }^{62}$ See Depledge (2005)
} 
Whereas sometimes there are legitimate reasons for restricting the access to certain documents during the meetings, there does not seem to be an overriding interest to withhold the information contained in these documents once the negotiating session is over. On the other hand, there are pressing reasons advocating for a broader release of such type of documents. Indeed, it is important that external stakeholders get "first hand" information to gain an accurate understanding of the process dynamics. Although the lack of access to certain documents is partly compensated by the summaries of the negotiations provided by the Earth Negotiations Bulletin ${ }^{63}$, the latter convey only a short overview of the principal debates that have taken place and represent no official source of information. Finally, the conference documents translate effectively the diverging views of Parties, providing thereby an interesting record of the arbitrages that were necessary to reach consensus. We suggest therefore that the release of documents which is destined to Parties only is kept to a minimum, and, unless there are compelling reasons, that all documents, including the non-papers and the Conference room papers, are published on the web in an adequate way and stored so as to allow stakeholders to accede them at a later stage. The webpage of the WTO may serve in this respect as a good example as to how information may be presented and retrieved in a userfriendly way. ${ }^{64}$

\subsubsection{Enhancing access to negotiation meetings}

As set out above, BINGOs have full access to the plenaries' sessions as well as to any openended contact groups unless at least one third of the Parties present object. ${ }^{65}$ As negotiations rarely take place in the plenary meetings ${ }^{66}$, it is important that BINGOs can assist regularly all the negotiation meetings of interest to them.

Since the launch of the AWG-LCA by the Bali Action Plan Parties usually split up in a multitude of contact, drafting, spin-off and other informal groups to negotiate and exchange views. Although no final decisions are taken by these groups, they are crucial for the outcome of the negotiations, allowing Parties to debate more openly and thereby creating an atmosphere more conducive to compromise. With the exception of the first and the last contact group meeting, these discussions have been held behind closed doors in recent times. ${ }^{67}$ As a result, interested stakeholders have been prevented from gaining a better understanding of the process, remaining dependent on second-hand information. Although there might sometimes exist good grounds for excluding external stakeholders, the openness of these meetings for NGOs is crucial and should remain the rule and not become the exception. If there is a problem of insufficient room space, some places may be set aside and allocated through a call for expressions of interests to relevant stakeholder groups or by an invitation made by the Secretariat to NGO constituencies to nominate a number of representatives. ${ }^{68}$ Another option could be, unless this is considered to prevent a frank debate,

\footnotetext{
${ }^{63}$ The Earth Negotiations Bulletin is prepared by IISD, a Canadian ENGO, which publishes daily summaries of the negotiations as well as a final summary of each session. See for instance the summaries of the Durban summit on the internet under http://www.iisd.ca/vol12/enb12534e.html.

${ }^{64}$ See on the internet under http://www.wto.org/.

${ }^{65}$ Art. 7 draft rules of procedures. Decision 18/CP.4 See also Depledge (2005: 218).

${ }^{66}$ The sizes of plenary meetings as well as the strict rules governing its procedures are not conducive to an "indepth and frank discussion”. See Yamin et al. (2004: 450).

${ }^{67}$ Information provided to the author by a staff member of the Secretariat.

${ }^{68}$ Müller (2011: 2).
} 
to have the meetings publicly webcast ${ }^{69}$ or at least made available to those stakeholders that have expressed their interest but were not able to do so physically. ${ }^{70}$

\subsubsection{Improving involvement in workshops}

In Cancun and more recently in Durban, Parties have decided to launch a series of workshops to explore new avenues. The aim of these workshops is to increase the understanding of certain aspects of an issue and to evaluate the pros and cons of possible options in the fledgling stages of the discussions. Certain of these workshops are of particular relevance for business actors, in particular in the domains of REDD + and new market mechanisms. Representatives of BINGOs are generally admitted to these workshops. They may however not take the floor, unless invited to do so. ${ }^{71}$ As a result, the creativity, the energy and expertise of the business sector can't be injected effectively into the process. Also, for stakeholders who are not present physically at these meetings, little information is made available. For instance, discussions are not webcast and may thus not be followed by interested stakeholders at a later stage. ${ }^{72}$ This may lead, as a recent forum of business stakeholders on new market mechanisms ${ }^{73}$ showed, to "a deep gap in understanding ...between those that are "insiders" (negotiators), and most of the stakeholders, that are called to contribute to the debate as future implementers, investors and regulators". ${ }^{74}$ This is clearly unfortunate, as the active involvement of the private sector is direly required to make these mechanisms operational.

\subsubsection{Mobilisation of business stakeholders through consultation processes}

If increased access to documents and debates allows business stakeholders to gain an improved understanding of the negotiation process, more will have to be done to enhance their participation and to transform their role from mainly passive observers into active advisors. In particular, channels of information which allow more systematic exchanges of ideas between the private sector and the relevant actors of the UNFCCC and vice-versa must be created. Ideally, business stakeholders should be actively approached at any stage of the negotiation process where they can provide valuable expertise. Stakeholder consultations should be put into place, encouraging business to invest in a new political space. To achieve this, new rules will have to be developed, following certain general principles and standards to ensure wide participation and transparency both to those who are directly involved and to the general public. ${ }^{75}$

A key issue that arises when setting up new consultation processes is to determine which body should be in charge of the logistics. Currently, the International Chamber of Commerce (ICC)

\footnotetext{
${ }^{69}$ Webcasts are nowadays provided for certain meetings. See for a list of them http://unfccc.int/press/multimedia/webcasts/items/2777.php.

${ }^{70}$ Müller (2011: 2).

${ }^{71}$ See for instance the workshop on new market mechanisms in Bonn on $19^{\text {th }}$ May 2012 on the internet under http://unfccc.int/files/bodies/awg-lca/application/pdf/information_note_nmm_rev.pdf.

${ }^{72}$ In recent sessions, some improvements may be noted. For instance, a summary and the slides of the presentations made at the workshop on a framework for various approaches on $19^{\text {th }}$ May 2012 have been published on the web. See on the internet under http://unfccc.int/meetings/bonn_may_2012/workshop/6661.php.

${ }^{73}$ See the workshops organised by the Centre of European Policy Analysis on new market based mechanisms on the internet under http://www.ceps.eu/taskforce/ceps-carbon-market-forum-new-market-mechanisms-under-awglca.

${ }^{74}$ Not published meeting notes of $23^{\text {rd }}$ February 2012 of the task force launched by the Centre of European Policy Analysis on new market based mechanisms.

${ }^{75}$ The rules have been codified in a document issued by the European Commission. See C(2010) 7649 final, see on the internet under http://ec.europa.eu/transparency/regexpert/PDF/C_2010_EN.pdf
} 
is the liaison entity between the business community and the Secretariat, playing the role of a focus point. ${ }^{76}$ For an enhanced participation of business stakeholders the actual structure is however clearly insufficient. To deal with the increased workload specific sections that would be responsible for coordinating the relations with the business sector should be created by the Secretariat and the new institutions established by the Cancun Agreements. ${ }^{77}$ The ICC could continue to play the role of coordinator with respect to BINGOs wishing to participate in the negotiation meetings, but would not be responsible for handling the consultation processes.

The question relating to who should be allowed to represent the business sector may not receive a straightforward answer. It will depend very much on the nature of the task and the role that the persons/entities are expected to play. Expertise may be provided by individuals appointed either in their personal capacity, by individuals representing stakeholders of a particular policy area as well as by individual companies and business organisations. ${ }^{78}$

Another important issue that has to be addressed is which rules should guide the selection process of potential participants. ${ }^{79}$ Different modes may be envisaged, depending in particular on a number of factors, such as the field of activities, the required expertise, the time frame and the modalities of the consultations. If individuals are appointed in their personal capacity, the selection process should guarantee a high level of expertise and, as far as possible, a geographical and gender balance. Furthermore, the candidates will have to be selected in such a way as to avoid any conflict of interests. As far as possible, public calls for applications should be issued. When this is not practicable, because a very specific expertise is required, experts should be chosen on the basis of objectively verifiable criteria. ${ }^{80}$

If individuals, companies or business associations represent the interests of a stakeholder group, a balanced representation of relevant stakeholders should be ensured, and when appropriate, individuals may be appointed through a self-selection process carried out by the stakeholders' group. ${ }^{81}$ In any case, clear terms of reference will have to guide the selection process and provide inter alia information on the identity of the participants, on the main activities carried out, on the meetings that take place and the funding available. ${ }^{82}$

An important aspect that needs further to be considered is whether consultation process necessarily requires a formal mandate by the Parties or whether more informal approaches may equally be encouraged. Interesting insights in this respect may be gained from the EU which has over time acquired a large experience regarding the interaction with a broad range of stakeholders, ranging from the organisation of symposia, the call for experts to broad econsultation $^{83}$ processes. Further, the WTO with the organisation of its online forum, where

\footnotetext{
${ }^{76}$ See Yamin (2004), Depledge (2005) WBCSD et al. (2010: 22)

${ }^{77}$ See for the current structure of the Secretariat on the internet under http://unfccc.int/secretariat/programmes/items/2098.php.

${ }^{78}$ See for a description of the different roles of these stakeholders WBCSD et al. (2010. 62).

${ }^{79}$ See in particular the selection process of expert groups by the European Union on the internet under http://ec.europa.eu/transparency/regexpert/faq.cfm?aide=2.

${ }^{80}$ See for instance the rules developed by the World Bank for the selection and employment of consultants on the internet under http://siteresources.worldbank.org/INTPROCUREMENT/Resources/278019-

1308067833011/Consultant_GLs_English_Final_Jan2011.pdf.

${ }^{81}$ See for instance the self-selection process carried out by the WBCSD at WBCSD(2010: 39).

${ }^{82}$ The United Nations Development Program (UNDP) has developed sophisticated rules notably on the procurement of services. See on the internet under http://www.undp.org/content/undp/en/home/operations/procurement/frequently_procuredgoodsandservices/.

${ }^{83}$ E-consultation is the use of electronic computing and communication technologies in consultation processes.
} 
experts from all around the world address in a joint effort major issues of the multilateral trading system, provides a good example of how a lively exchange of ideas can be fostered. ${ }^{84}$

The lessons that can be drawn from business engagement in the UNFCCC itself suggest that informal dialogues can sometimes foster a higher degree of trust and understanding between civil society and the Parties than formal channels of interaction. ${ }^{85}$ An interesting example of such an informal approach is provided by the recent high-level policy dialogue on the CDM. ${ }^{86}$ It was launched by the Executive Body of the CDM (EB) in 2011 and aims to engage civil society, policymakers and market participants in a year-long dialogue. A high-level panel composed of representatives of civil society was set up which during one year interacts with CDM stakeholder groups through a range of means, including online communications, submissions, individual discussions and stakeholder meetings. Summaries of the meetings are regularly posted on the website and the high-level panel's final report will be submitted to the EB and made public.

It is too early to draw final lessons from this interesting initiative which testifies for the need of an enhanced dialogue with civil society at large and the business sector in particular by the UNFCCC process. Clearly, such a setup bears the advantage of speed, flexibility and relatively low costs. On the other hand, no control can be exerted on the process with respect to the guarantee of criteria such as non-discrimination, geographical as well as gender balance. The lack of control is however compensated to a certain extent by the high transparency and the openness of the process towards all interested stakeholders. ${ }^{87}$ Further, the ultimate outcome, a recommendation submitted to the EB, has no legal force and will be given consideration exclusively on the merits of its arguments.

While the immediate benefits of informal approaches such as the CDM policy dialogue are obvious and particularly appropriate for platforms with a temporary activity, it seems advisable that permanent bodies with a sizable impact on the process are governed by formal rules. The participation models of the OECD, the Montreal Protocol and the APP may in this respect provide valuable guidance. Through the setup of permanent policy groups, BIAC members have indeed been very effective in providing both technical and political advice to the OECD. The establishment of a permanent panel comprising business representatives under the Montreal Protocol has ensured that the Parties to this treaty may at all times engage in a dialogue with experts on technical and scientific issues. Both organisations benefit thus from a facilitated access to the know-how of the business community, which is able to contribute directly to an informed decision-making process. Finally, the establishment of public-private task forces under the APP has greatly enhanced the sharing of information and the access to existing technologies and know-how among its participants and thereby improved effectively the implementation process. ${ }^{88}$

These examples show that there exist manifold options to increase the participation of business stakeholders in the UNFCCC process, both informal and formal. While for certain topics, such as REDD+ and in the field of new market mechanisms, the setup of permanent advisory bodies might provide the most effective tool for fostering an ongoing and more

\footnotetext{
${ }^{84}$ See on the internet under http://www.wto.org/english/forums_e/chat_e/chat_e.htm.

${ }^{85}$ WBCSD et al. (2010: 63).

${ }^{86}$ See on the internet under http://cdmpolicydialogue.org/

${ }^{87}$ The website displays all the names of the members of the high-level panel, publishes all submissions and provides for a record of all the meetings.

${ }^{88}$ See Fujiwara (2012: 11).
} 
structured dialogue with business and industry, more informal venues may be preferred for other issues.

Indeed, as the experience with the BCM teaches permanent bodies or policy groups comprising business representatives may be difficult to create by an organisation such as the UNFCCC with near universal membership and a consensus-based decision-making process. This difficulty may be partly addressed through an evolutionary approach. As Fujiwara suggests an informal body in the form of an existing industry association may in a preliminary stage of discussions assume a limited steering role and, if the experience is considered fruitful, be transformed at a later stage into a fully-fledged advisory body to the UNFCCC. ${ }^{89}$ Overall, a pragmatic and tailor-made approach is probably preferable to a highly formalised process that prevents creative and new models of interactions.

To sum up, the UNFCCC should arrange new consultation processes for business stakeholders enabling regular multi-stakeholder dialogues and catalysing collective learning processes. ${ }^{90}$ To this effect, both the Secretariat and the new institutions created by the Cancun Agreements should set up specialised sections entrusted with the task of organising the interaction with business and industry and possibly also other stakeholders of civil society. A wide array of instruments and cooperation forms may be envisaged, including in particular symposia with relevant industry sectors and companies, call of expert groups, online consultations and new tools such as online fora and other social media of the internet. To guarantee the full transparency of these processes, dedicated websites on the model of the CDM policy dialogue should be established which inform a broader public on the conditions of participation, the agenda of scheduled meetings and their possible outcomes. Finally, the selection of participants should be guided by transparent rules that ensure a balanced input of companies and sectors but provide at the same time the necessary flexibility to accommodate specific circumstances and new models of interaction.

\section{Conclusions}

Significant progress in the multilateral negotiations on climate change will only be made if civil society and in particular business and industry stakeholders are fully committed to the process and actively contribute to shape it. So far, however, the creativity and the potential of the private sector have not yet been fully exploited. Admitted to the international negotiations in the form of BINGOs, business and industry entities continue to be far more active at the national than the international level. Their pro-active investment in new international policy spaces is hence highly warranted, especially as the climate regime moves from formulating a broad framework for action towards more implementation.

An enhanced participation of the private sector in the multilateral climate regime is however not viewed by all stakeholders positively. In particular, environmental NGOs fear that companies which business models depend on the sale of carbon-intensive goods and services will play a more obstructive than constructive role. This risk may not be discarded lightly and new rules on enhanced participation of business and industry will have to give this aspect due consideration. On the other hand, it is important that all actors can voice their concerns so that they can be addressed adequately.

\footnotetext{
${ }^{89}$ See Fujiwara (2010: 9).

${ }^{90}$ See Andrade (2008: 15).
} 
Lessons on how to organise increased involvement of business and industry may be drawn in particular from the Montreal Protocol on ozone depleting substances, the OECD, the WTO, the EU and the APP. These international organisations display a wide variety of forms of cooperation, ranging from formal arrangements like the setup of permanent expert panels, policy groups and public-private task to more informal modes of interactions, including the call of temporary expert groups, the organisations of seminars, conferences and online consultations.

A preliminary condition for an effective dialogue with business and industry stakeholder is a transparent process, including an encompassing access to negotiation documents, a userfriendly display of information and adequate participation modalities with respect to negotiation sessions. Although some progress has been made recently, many conference documents are not published on the web and important negotiation fora remain closed to NonParties. As a result, access to relevant information remains a challenging task for many external stakeholders.

To transform business and industry stakeholder from mainly passive observers into active advisors more than increased transparency and access to meetings is however necessary. Systematic stakeholder consultations will have to be implemented, allowing a regular exchange of information and the effective channelling of the expertise of the private sector into the negotiation process. This may be achieved if new modes of interaction are actively pursued, including both formal arrangements and more informal venues. Indeed, only if government representatives and business stakeholders interact on a continuous basis will they learn more about each other's concerns and eventually contribute to give birth to new ideas that might prevent a gradual "ossification” of the multilateral climate regime. ${ }^{91}$

\section{Bibliography}

Andrade Celio, Taravella Romain (2008). Le rôle du secteur privé dans la gouvernance internationale de l'environnement : de « rule-taker » à « rule-maker » ? 12th General EADI Conference, Geneva.

Bausch Camilla, Mehling Michael (2011). Addressing the Challenge of Global Climate Mitigation An Assessment of Existing Venues and Institutions, Friedrich Ebert Stiftung.

Charnovitz Steve (2001-2002). The WTO and Cosmopolitics, The Journal of International Economic Law, v. 7, n. 3, 675-682.

Chasek Pamela S.; Wagner Lynn M. (eds) (2012). The Roads from Rio: 20 years of global environmental negotiations, p. 19- 38.

Depledge Joanna (2005). The organization of global negotiations: constructing the climate change regime, Earthscan, London.

Depledge Joanna (2006). The opposite of learning: Ossification in the climate change regime (2006), Global Environmental Politics, v. 6, n. 1, p. 1-22.

Depledge Joanna (2008). Striving for no: Saudi Arabia in the climate change regime, Global Environmental Politics, v. 8, n. 4, pp .9-35.

\footnotetext{
${ }^{91}$ Depledge (2006: 2).
} 
Depledge Joanna, Yamin Farhana (2009). The global climate change regime: A defence (2009), in Helm D. and Hepburn C. (eds.), The Economics and Politics of Climate Change, Oxford University Press, Oxford, chapter 21.

Dunoff Jeffrey L. (1998). The misguided debate over NGO participation at the WTO, Journal of International Economic Law, p. 433 - 456.

Fujiwara Noriko (2010). Sectoral Approaches to Climate Change: What can industry contribute? CEPS Special Reports.

Fujiwara Noriko (2012). Sector-specific Activities as the Driving Force towards a LowCarbon Economy: From the Asia-Pacific Partnership to a Global Partnership, CEPS Policy Briefs.

Müller Benito (2011). UNFCCC - The Future of the Process: Remedial Action on Process Ownership and Political Guidance, Climate Strategies Brief.

Oberthür Sebastian (2011). Global Climate Governance after Cancun: Options for EU Leadership, The International Spectator 46, v. 1, p 5-13.

Quittkat, B. Finke (2008). The EU Commission Consultation Regime, in: Kohler-Koch Beate, De Bièvre Dirk, Maloney William, Opening EU-Governance to Civil Society, Gains and Challenges, CONNEX Report Series n.5, Mannheim, p. 187 ff.

Schröder Heike, Lovell Heather (2011). The role of non-nation-state actors and side events in the international climate negotiations, Climate Policy 12, v. 1, p. 23-37.

Vormedal Irja (2008). The Influence of Business and Industry NGOs in the Negotiation of the Kyoto Mechanisms: the Case of Carbon Capture and Storage in the CDM, Global Environmental Politics, v. 8, n. 4, p. 36-65.

World Business Council for Sustainable Development (WBCSD), Ecofys, Climate Focus (2010). Private Sector and the UNFCCC Options for Institutional Engagement,

Yamin Farhana, Depledge Joanna (2004). The international climate change regime: a guide to rules, institutions and procedures, Cambridge University Press, Cambridge. 